\title{
PAZ, QUESTÕES RACIAIS E A CONSTRUÇÃO DE FRONTEIRA: OUTRAS PERSPECTIVAS SOBRE A MINUSTAH.
}

Peace, racial issues and the production of boundaries: other perspectives about MINUSTAH.

\author{
Pedro Gomes de Souza Barros ${ }^{1}$
}

\section{Resumo}

Este artigo analisa narrativas de haitianos sobre a paz promovida pela MINUSTAH. Através de um 'diálogo' entre diferentes autores brasileiros que estudam paz e Operações de Paz da ONU e com atenção à fronteira e questões raciais, este artigo confronta narrativas anfitriãs e não-anfitriãs, problematizando a discussão brasileira sobre paz.

Palavras-chave: Paz; questões raciais e fronteira; MINUSTAH.

\begin{abstract}
This article analyses Haitians narratives about the peace that MINUSTAH has promoted. Through a 'dialogue' between different Brazilian authors that study peace and UN Peace Operations, and attentive to boundary and racial issues, this article confronts host narratives with non-host narratives, problematizing the Brazilian discussion about peace.
\end{abstract}

Key-words: Peace; racial issues and boundaries; MINUSTAH.

\section{Introdução}

Em 2007, o General Augusto Heleno Ribeiro Pereira afirmou que a MINUSTAH é uma operação de imposição da paz. Tal afirmação, feita pelo primeiro Force Commander da Missão das Nações Unidas para a Estabilização do Haiti (MINUSTAH), é um indício de como paz tem, muitas vezes, sido entendida: algo singular, que é único.

Desde 2004, quando o Brasil assumiu a liderança militar da MINUSTAH, a discussão sobre paz, no que tange à participação brasileira em Operações de Paz (OPs), vem ganhando relevância no Brasil. Todavia, essa discussão tem sido caracterizada por diferentes abordagens. Enquanto alguns autores corroboram o entendimento do Gal. Pereira, outros adotam uma postura chamada crítica sobre a singularização da paz.

\footnotetext{
${ }^{1}$ Mestre em Relações Internacionais, PUC-Rio, Rio de Janeiro, Brasil. 
Com atenção a estas diferentes escolhas analíticas sobre paz e a atuação brasileira em OPs, neste artigo será analisada a paz que tem sido imposta no Haiti a partir de narrativas anfitriãs. Tais narrativas serão interpretadas à luz de uma perspectiva que explora questões raciais e a produção de fronteira, ambas socialmente construídas pela paz e também construindo-a. 0 argumento apresentado adiante é que o tímido debate no Brasil precisa ser mais inclusivo quanto às vozes anfitriãs de OPs e mais crítico quanto a questões raciais.

Para alcançar tal objetivo o restante do artigo será dividido em quatro partes. Na primeira, serão abordados três artigos produzidos no Brasil que trabalham paz e participação brasileira na MINUSTAH a partir de uma singularização da paz. Na segunda, serão abordadas propostas teóricas de estudos críticos de autores brasileiros sobre paz. Na terceira, a partir do diálogo entre as diferentes análises, será argumentado em favor de uma análise que dê ênfase à produção de fronteira e questões raciais. Na quarta, através da perspectiva de haitianos serão analisados documentos e estudos sobre a MINUSTAH.

\section{Paz como singular e a atuação brasileira em OPs}

Um autor de grande relevância na discussão sobre paz no Brasil é Sérgio Luiz Cruz Aguilar. Em um artigo para o livro Reflexões Sobre a Paz, de 2014, Aguilar, baseando sua análise nas propostas de paz perpétua de Emmanuel Kant, argumentou que a paz perpétua só pode ser alcançada através de Direitos Civis - que garantem liberdade aos indivíduos diante do Estado - e do Direito das Gentes - que garante segurança para o menor dos Estados.

Através desta proposta kantinana, o autor argumentou que as OPs são úteis como ferramenta para a solução de conflitos por possibilitarem um ambiente anárquico pacífico entre Estados. Para chegar a essa defesa, o autor buscou entender os conflitos atuais que têm sido alvo de operações de paz e, depois, analisou os programas realizados pelas operações para que a paz duradoura (segundo o autor) seja factível.

Ao analisar os conflitos, Aguilar (2014) afirmou que esses são os mesmos desde a antiguidade e que são motivados por uma de duas razões: individual ou coletividade social (AGUILAR, 2014, p. 103). A individual é: “...a violência como uma necessidade biológica, ou como um comportamento psicológico de resposta a um estímulo que se 
exterioriza diante de uma frustração..." (AGUILAR, 2014, p. 102). A segunda motivação pode ter origem na luta entre grupos, incerteza de detenção de poder entre as elites dirigentes, transferência de sentimento agressivo para outro grupo em decorrência de imperativos tradicionais e ideológicos ou por razões culturais (AGUILAR, 2014).

A partir do diagnóstico acima o autor concluiu que "a história da humanidade é uma história de guerras" e que não foi alterada nem mesmo pelo surgimento do Estadonação a partir do século XVII. Por esse entendimento Aguilar apontou para como a resolução de conflitos pode ser alcançada:

"Pode-se, então, inferir sobre a importância da guerra para o Estado, que esse
ator permanecerá com o poder de decidir por ela ou pela paz, e que o cenário do
século XXI ainda é o da "anarquia" onde o entendimento entre os principais atores
do sistema continuará fundamental para a administração e a resolução de
conflitos" (AGUILAR, 2014, p. 103).

Preocupado com uma relação de cooperação entre os principais atores do sistema internacional - Estados-nação -, Aguilar (2014) então se voltou para processos que a $\mathrm{ONU}$, segundo ele, deve promover ao ter como fim a paz:

\begin{abstract}
"Dessa forma, para a resolução de um conflito deve-se promover o consenso e a cooperação e implica, normalmente: no controle da violência física (separação das partes em luta utilizando militares e policiais); criação de ambiente favorável ao diálogo (por meio de incentivos ou coerção - sanções); uso da diplomacia para estabelecer acordos (se inicia com acordos de cessar fogo para, numa última fase, serem estabelecidos acordos de paz); e eliminação das causas e condições responsáveis pelo conflito (atuando como prevenção contra uma nova violência)" (AGUILAR, 2014, p. 105).
\end{abstract}

A partir desta análise sobre o conflito e sobre sua resolução, o autor apontou as ações essenciais para alcançar a paz e, portanto, que não podem deixar de ser realizadas durante as OPs. Essas ações são:

“...restauração da habilidade do Estado em prover segurança e manter a ordem
pública, fortalecimento do estado de direito e do respeito aos direitos humanos,
apoio à emergência de instituições políticas e legítimas e a processos
participativos, e promoção da recuperação social e econômica e do
desenvolvimento, que inclui o retorno seguro o reassentamento de desalojados e
refugiados" (AGUILAR, 2014, p. 108).

Depois, foram listados quatro programas fundamentais: DDR (Desarmamento, Desmobilização e Reintegração), deminagem (retirada de minas terrestres que são instaladas durante o período de conflito), promoção e proteção dos direitos humanos e, por útlimo, a realização de projetos de infra-estrutura voltados para a geração de emprego e renda (AGUILAR, 2014). Portanto, a paz (algo singular) duradoura, para o autor, é fruto do sucesso destes programas. 
Corroborando com a singularização da paz sustentada por Aguilar (2014), Filipe Nasser (2012) analisou a participação brasileira em OPs dando destaque a quatro delas: Angola, Moçambique, Timor-Leste e Haiti. Essas participações, segundo o autor, têm duas características em comum:

\begin{abstract}
"A tese apresentada neste capítulo é que a participação brasileira nas OPs da ONU em Angola, Moçambique, Timor-Leste e Haiti esteve informada tanto por um sentido de projeção de poder nas relações internacionais, como pelo desejo de prestar solidariedade ativa a sociedades vitimadas por conflitos armados" (NASSER, 2012, p. 215).
\end{abstract}

As características estão, segundo Nasser (2012), relacionadas com o multilateralismo onusiano brasileiro que caminha junto com a participação verdeamarela em OPs. Tal correlação pode ser notada pelo aumento da participação brasileira em operações de paz desde 1989, ano que o Brasil fechou o primeiro biênio como membro não permanente do Conselho de Segurança (CS), após décadas de distaciamento: antes de 1989, foram sete participações em OPs; após, o número quadruplicou, 28 (NASSER, 2012, p. 2016). Importante ressaltar que a participação brasileira está diretamente relacionada com o aumento do número de OPs desde a década de 1990.

Nasser (2012) apontou que um novo modelo de participação brasileira começou de "forma acanhada", mas que o Brasil tinha ciência do papel que poderia exercer. Tal observação se pautou na correlação entre expressão política e participação em OPs que pôde ser extraída das palavras do 'Force Commander' brasileiro na UNAVEM II (United Nations Angola Verification Mission II), General Lélio Gonçalves Rodrigues da Silva, entre 1993 e 1994, em Moçambique: "nossa participação com tropa armada tem sido tímida, se comparada à participação de diversos outros países, de muito menor expressão política, econômica e, principalmente, militar" (Nasser, 2012, p. 217 Apud. AGUILAR, 2005).

Seguindo para analisar esse novo modelo, o autor observou que em 1996, quando o Brasil participava da operação em Angola (UNAVEM II), ocupou a posição do quarto maior contribuinte de tropas para OPs. Depois, o Brasil participou - "ainda mais tímido do que se poderia esperar", mas com "disposição" - no esforço de pacificação e reconstrução do Timor-Leste (NASSER, 2012, pp. 219 e 220).

Ao analisar o quarto destaque, a estabilização do Haiti, Nasser (2012) observou que o Brasil (até 2012) contribuía com o maior contingente por país - 1.200 oficiais a cada turno. 0 número cresceu imediatamente após o terremoto de janeiro de 2010, que 
deixou mais de 300 mil mortos; “...Congresso Nacional brasileiro autorizou o envio de 1.300 soldados adicionais para integrarem a MINUSTAH, somando-se aos 1.200 capacetes azuis brasileiros que já se encontravam no terreno" (NASSER, 2012, p. 222).

Por fim, após analisar as atuações brasileiras o autor apontou que, principalmente a liderança exercida na MINUSTAH, é uma busca por "ascensão brasileira nas fileiras internacionais”: “...a decisão de liderar o componente militar da MINUSTAH... foi irremediavelmente associada à campanha brasileira por um assento permanente no CSNU" (NASSER, 2012, p. 229).

Corroborando o pressuposto de Nasser (2012) - interesse brasileiro por ascenssão no cenário internacional junto com solidariedade a sociedades vitimadas - e buscando interpretar o papel do Brasil na resolução (que está em diálogo com as propostas de Aguilar (2014)) do que chamou de crise haitiana, Danilo Marcondes de Souza Neto observou as diferentes atividades exercidas no terreno. Todavia, elas foram analisadas quanto à necessidade que o Brasil assumiu de obter êxito na missão. Explicou Neto:

“...ao colocar a participação na MINUSTAH como um medidor da capacidade do país para assumir responsabilidades internacionais do nível de um membro permanente do CSNU o Brasil assume um risco, porque passa a depender do êxito de sua participação na missão como forma de legitimar seu pleito por um assento permanente" (NETO, 2012, p. 247).

Relacionando o interesse nacional com a necessidade de êxito na missão, Neto (2012) destacou uma visão, particular, do Brasil: segurança anda de mãos dadas com o desenvolvimento econômico (NETO, 2012, p. 248). A partir dessas considerações e corroborando a afirmação do primeiro 'Force Commander' da MINUSTAH, Gal. Pereira, de que ela é uma "missão de imposição da paz" (NETO, 2012, p. 246) o autor analisou a (imposição da) paz através de atividades como patrulhas a pé e com blindados, pacificação da favela de Bel Air, ações não militares - retirada de lixo das ruas, prestação de atendimento médico e ondontológico e atividades culturais -, combate à gangues armadas, plano de captura dos detentos foragidos desde o terremoto de janeiro de 2010, uma reformulação das atividades que foi necessária após o terremo entre outras (NETO, 2012). Assim, Neto (2012) analisou a paz ou sua imposição no Haiti como algo que advém da resolução de conflitos e que está intrínseca aos interesses nacionais e desejo solidário do Brasil sem, todavia, indagar qual paz o Brasil contribui para impor. 
Os três artigos, brevemente analisados aqui, evidenciam como a singularização da paz está presente no tímido debate que ocorre no Brasil. Entretanto, há outros autores brasileiros que problematizam tal conceituação da paz.

\section{Estudos críticos sobre paz nos estudos de OPs}

Paralelo às publicações citadas acima, Áureo Toledo (2013) se propôs a uma sistematização de estudos críticos sobre paz. Tal sistematização tem como finalidade apontar desafios teórico-metodológicos "que os estudos sobre peacebuilding precisam responder para se consolidarem como potenciais concorrentes - e não apenas uma nova forma de aplicação - da paz liberal" (TOLEDO, 2013. p. 48). Mas o que é paz liberal?

Toledo (2013), influenciado pelos escritos de Oliver Richmond, expôs que paz liberal tem sido o termo empregado para se referir à paz que OPs têm, muitas vezes, imposto em países onde atuam mediante "ações cujos objetivos a serem perseguidos são a democratização, estabelecimento do Estado de Direito, proteção dos direitos humanos e promoção de uma economia orientada ao mercado" (TOLEDO, 2013, p. 48). 0 autor define tal perspectiva como crítica e divide-a em três eixos: críticas reformistas, críticas estruturais e virada local.

As críticas reformistas são analisadas através das contribuições de Simon Chesterman e Roland Paris. Para Toledo (2013) os autores críticos reformistas não questionam o projeto intelectual e político que está na base das ações das OPs, mas sim a forma como são implementadas (TOLEDO, 2013, p. 50).

Como exemplo das contribuições de Chesterman analisadas por Toledo (2013) pode-se destacar o papel da administração transicional (transicional administration"). Toledo apontou que Chesterman sustenta uma necessidade de mudança da administração transicional, uma vez que a administação local deficiente que suscitou uma intervenção. Entendendo que é a falta de instituições democráticas fortes que coloca em risco a paz, Chesterman argumenta em favor de uma administração "mais colonial”. Por essa proposta, percebe-se que Chesterman não é crítico à paz liberal, mas busca meios de reformar a atuação das OPs para que essas sejam mais exitosas quanto a implementação ou imposição da paz liberal.

Semelhante à Chesterman, Paris também, como apontou Toledo (2013), se caracteriza por proposta reformista. Como exemplo pode-se destacar a proposta de 
Institucionalização antes da Liberalização ("Institutionalization before Leberalization"). Toledo (2013) observou que tal proposta se pauta no entendimento de que as comunidades anfitriãs apresentam lacunas institucionais que impedem a manutenção da paz liberal. Portanto, a reforma da implementação da paz liberal, ou seja, das ações das OPs é fundamental para os reformistas.

As críticas estruturais foram analisadas através das contribuições de Mark Duffield, Michael Pugh, David Chandler e Ian Taylor. Para Toledo (2013) os autores críticos estruturais têm como inspiração ideias neogramscianas e pós-estruturalistas e:

\footnotetext{
"questionam, por exemplo, se as causas dos conflitos em questão não seriam intrínsecas ao funcionamento do sistema capitalista internacional, ou mesmo se as operações de peacebuilding contribuiriam para a manutenção da atual ordem internacional" (TOLEDO, 2013, p.55).
}

As contribuições de Pugh e Taylor são analisadas a partir das respectivas preocupações com a manutenção das desigualdades do sistema internacional mediante posição dos interventores em definerem de forma depreciativa os anfitriões e suas instituições políticas. Através de tal divisão Pugh identifica a manutenção da desigualdade via promoção de privatizações e criação de ambiente externo favoravel ao capital internacional (TOLEDO, 2013).

Ainda no eixo da crítica estrutural, mas sob influência pós-estruturalista, principalmente dos trabalhos de biopoder de Foucault - Duffield, apontou Toledo (2013), dá ênfase à uma mudança no sistema internacional a partir da década de 1970. Pautado por um movimento de mais concentração e exclusão, o sistema internacional estaria mais preocupado em manter os problemas do Sul - região que não atingiu o desenvolvimento dos países considerados outrora 'primeiro mundo' - no Sul, fazendo das OPs um meio de controlar as populações anfitriãs a fim de manter a desigualdade internacional. A crítica se mantêm na estrutura do sistema como impulso para atuação das OPs (TOLEDO, 2013).

Por último, foram analisadas contribuições de Chandler. Como exemplo, pode ser destacada a mudança entre as atuais intervenções e as realizadas no pós-Segunda Guerra Mundial. Toledo (2013) destacou que, para Chandler, as atuais intervenções buscam negar as responsabilidades com a reconstrução classificando-as como científicas. Se na Alemanha e Japão do pós-guerra houve uma preocupação em obter legitimidade por parte das respectivas populações quanto à reconstrução, Chandler 
destacou que na Bósnia, Kosovo e Iraque houve pouca participação local (TOLEDO, 2013). Sendo assim, o entendimento sobre o sistema é essencial para os críticos estruturais.

Já as críticas da virada local são caracterizadas por uma crítica ao projeto liberal de reconstrução e por uma atenção à dinâmica local como uma tentativa de construção de uma paz duradoura - que em nada significa a paz duradoura defendida por Aguilar (2014). Toledo analisou as contribuições de Oliver Richmond e Roger MacGinty (TOLEDO, 2013, p. 63).

Como exemplo da análise de Toledo (2013) sobre os estudos de Richmond pode ser destacada o que o último definiu como quarta geração dos estudos sobre operações de paz. Para Richmond tal geração é marcada por uma busca em dar solução às críticas feitas aos estudos da terceira geração que teriam dificuldade em "lidar com temas como justiça e reconciliação, identidade, gênero e pelo caráter impositivo da paz uma vez que há pouco diálogo com a população local" (TOLEDO, 2013, p. 66). Nessa quarta geração há um debate sobre como a reconstrução sendo feita por atores não estatais são formas de controle da população local ou de emancipação do modelo de paz liberal (TOLEDO, 2013).

Quanto as contribuições de MacGinty, Toledo destacou duas de ordem teóricometodológicas. A primeira é a necessidade de dar atenção ao processo de hibridização das populações que é uma correlação entre:

"(1) a habilidade e poderes dos agentes externos em forçar a observância (compliance) do modelo liberal de construção da paz; (2) os incentivos externos para a instalação da paz liberal; (3) a habilidade dos atores locais em resistir, ignorar ou se adaptar as intervenções; e, por fim, (4) a habilidade desses mesmos atores em apresentar e manter alternativas ao modelo liberal" (TOLEDO, 2013, p. 67 Apud. MAC GINTY, 211).

E a segunda é a necessidade de questionar os indicadores que moldam o entendimento sobre paz, compreendida mediante definição negativa (ausência de conflito). Toledo (2013) destacou que para MacGinty, os novos indicadores devem ser particulares de cada sociedade e devem ser formulados de baixo para cima - definidos e empregados pela população local. Dessa forma, as propostas teóricas no eixo da virada local buscam uma maior participação das populações anfitriãs na construção da paz para suas respectivas sociedades. 
Estabelecendo um diálogo entre o artigo de Toledo (2013) e de Aguilar (2014) abordados acima pode-se identificar as respectivas escolhas analíticas dos autores. Por um lado, Aguilar (2014), a partir de uma singularização da paz, fez uma análise das OPs com um propósito de apontar lições aprendidas. Por outro, Toledo (2013) buscou indagar a ideologia que está por trás de tal proposição. Essas respectivas escolhas analíticas estão no cerne do tímido debate sobre paz no Brasil, principalmente, quanto à participação brasileira em OPs.

Seguindo nas proposições críticas quanto à paz liberal, Ramon Blanco, ao analisar o processo de construção da paz no Timor-Leste, trilhou um caminho distinto de Nasser (2012). Enquanto o último, com foco na participação brasileira, buscou destacar a contribuição verde-amarela para a pacificação e reconstrução do TimorLeste, o primeiro se preocupou em classificar que tipo de paz foi promovida e classificada como um sucesso.

Blanco (2015) deu atenção ao que ele classificou de "shortcoming" durante o processo de implementação da paz no Timor-Leste. 0 autor não compartilha do entendimento que está em Nasser (2012) quanto ao sucesso do que o último definiu como pacificação. Para Blanco (2015) os eventos violentos de 2006 e o atentado aos primeiro-ministro e presidente timorense dois anos depois são indicativos da fragilidade da paz. Todavia o autor dá foco a dois eixos: limitações estruturais da ONU e negligência por parte da ONU quanto à realidade timorense (BLANCO, 2015, p. 50).

O primeiro eixo foi marcado por competição entre diferentes departamentos da ONU (como DPKO - Department of Peacekeeping Operations - e DPA - Department of Political Affairs), pela falta de possibilidade da UNTAET (United Nations Transitional Administration in East Timor) em acomodar a participação timorense nas tomadas de decisão e também nos treinamentos conflituosos que as forças policiais e militares receberam que culminaram em tensão política (BLANCO, 2015). 0 segundo eixo, para citar alguns fatores, foi marcado pela negligência da ONU quanto às disputas entre as elites políticas timorenses, as disputas entre polícia e forças armadas, a insatisfação por parte das forças armadas e a não reincorporação de guerrilheiros às forças armadas (BLANCO, 2015, p. 52).

Esses eixos, apontou Blanco (2015), demonstram o quanto a paz, que a ONU classifica como um sucesso, implementada no Timor-Leste, não comporta a realidade 
local. Portanto a paz, a qual Nasser (2012) de forma exitosa indicou a participação brasileira, é um produto, seguindo a escolha analítica de Blanco (2015), dos interventores. Esse diálogo estabelecido aqui suscita indagações quanto à imposição que o Brasil corrobora no Haiti via MINUSTAH: qual a paz imposta? Antes de buscar uma narrativa para responder a essa pergunta é importante se debruçar sobre duas características do tímido debate no Brasil.

Dialogando com essas escolhas acima indicadas, é possível identificar uma característica da discussão sobre paz; ainda que tímida a discussão é rica em proposições teóricas e analíticas. A partir do diálogo aqui desenvolvido é importante evidenciar duas características analíticas da discussão: a produção de fronteiras e a pouca atenção dedicada a questões raciais.

\section{Fronteira e questões raciais}

A fronteira nos estudos sobre paz, principalmente quando abordadas OPs, tem ganho pouca atenção. Todavia, está na base analítica dos autores que debatem o tema. Pela breve análise do trabalho de Aguilar (2014) é possível perceber que a epistemologia empregada pelo autor é uma epistemologia racionalista que não questiona a construção do Estado-nação e tampouco conceitos como de paz (kantiana) duradoura. Os atores, Estados-nação, trabalhados por Aguilar (2014) são os mesmos desde o século XVII e as guerras se repetem por dois tipos de motivações desde a antiguidade; há uma essência da paz, do conflito e do ator a solucionar este e implementar aquela.

Trabalhando com essências, Aguilar (2014) então se propôs a oferecer soluções técnicas apontando quais ações e programas devem ser realizados para o sucesso da operação. Tal abordagem tem como base uma linha que divide a função de cada um no processo de resolução de conflitos: de um lado, está(ão) quem implementa a paz; de outro, o(s) que recebe $(\mathrm{m})$ a paz. Essa linha é a fronteira entre os atores.

Seguindo nessa perspectiva, Nasser (2012) fez um breve histórico sobre a participação brasileira em OPs na qual não questionou como a fronteira entre o Brasil e os países-anfitriões foi sendo naturalizada entre países. No entanto, ainda que não problematizando a fronteira, Nasser (2012) se utilizou dela para analisar a participação brasileira: as atividades de responsabilidade do Brasil e suas potencialidades, por 
exemplo. Tal recorte, pressupõe uma fronteira natural entre aquele que está em conflito e um outro, que pode acabar com o conflito.

Ainda nessa perspectiva, Neto (2012) também naturalizou a fronteira ao apontar que a crise haitiana que suscitou ação da ONU foi oriunda de uma questão interna e, por consequência, da falta de capacidade interna haitiana de solucioná-la:

"No início de 2004 ocorreu um agravamento da crise política no Haiti, que se
manifestava desde a eleição presidencial de 2000 , na qual Jean-Bertrand Aristide
havia sido eleito em um processo eleitoral marcado por baixa participação e
boicote da oposição.
Em 26 de fevereiro o Conselho de Segurança da Organização das Nações Unidas
(CSNU) demonstrou preocupação com a crise no país, destacando o receio acerca
de possíveis efeitos desestabilizadores para a região, bem como a preocupação de
que as divergências políticas, o aumento da violência e a quebra da lei e da ordem
pudessem levar a um banho de sangue. O Conselho alegou que iria considerar o
seu possível envolvimento na crise, inclusive por meio de uma força internacional"
(NETO, 2010, p. 243 e 244).

Devido ao ocorrido internamente, o Haiti passou a ter a função de receber a paz que países como o Brasil podiam implementar (ou impor). Essa divisão de tarefas foi fruto de uma produção de fronteira que, na perspectiva de Neto (2012), foi naturalizada. Assim, os três autores, naturalizando fronteiras, observaram um único caminho: paz como algo singular e de posse de determinado ator, posicionado em determinado lado da fronteira.

Diferentemente de Aguilar (2014), Nasser (2012) e Neto (2012), mas também trabalhando implicitamente com fronteira, Toledo (2013) e Blanco (2015) entenderam a fronteira como algo construído socialmente. Enquanto para os primeiros, a partir de essências, há uma fronteira prévia às OPs, para os últimos essa fronteira é fruto de interação social permeada de relações de poder que definem quem decide qual paz será a paz.

Dessa forma, ao propor uma nova abordagem de discutir paz, Toledo (2013) e Blanco (2015) também problematizaram a fronteira: olhando-a como socialmente construída. Assim, foi evidenciado um local de produção de fronteira que não é puramente geográfico, como se poderia supor pelas perspectivas racionalistas, mas sim discursivo. Logo, a fronteira não é algo natural e prévio à operação, mas é analisada como construída durante a implementação, ou imposição, da paz.

Corroborando com o entendimento da fronteira como algo socialmente construído, em 2012, Marta Moreno, Maíra Gomes e Carlos Braga analisaram a 
participação brasileira na MINUSTAH de forma distinta da feita por Neto (2012). Enquanto o primeiro não problematizou a paz imposta, Moreno et al. (2012) analisaram a paz que os países latino-americanos, com ênfase no Brasil, vêm promovendo. Tal promoção se distingue da paz liberal pela perspectiva pós-colonial dos países latinoamericanos e das demandas locais (MORENO et al., 2012).

Todavia os artigos, críticos ou não, demonstram que o tímido debate sobre paz no Brasil é ainda mais tímido quanto a questões raciais. Tal timidez não é despropositada, mas é fruto de uma abstração teórica. Esta, por sua vez, como observado por Sankaran Krishna (2006) é uma ferramenta útil que possibilita um conhecimento sobre determinado assunto. No entanto, ela nunca está fora das relações de poder (KRISHNA, 2006, p. 90). Para demonstrar essa abstração recorrente nos estudos de Relações Internacionais, o autor apontou para como os Cem Anos de Paz na Europa (no século XVIII), estudados por muitos teóricos, não contabiliza as guerras entre potências imperialistas europeias e os povos que foram colonizados. Ou seja, não problematiza como em determinado espaço, Europa, foi possível não haver guerra.

Krishna (2006) apontou que tal recorte não é somente uma abstração geográfica. As guerras do período e muitas outras que possibilitaram a colonização do que não era Europa desde o final do século XV foram pautadas por hierarquias raciais. Portanto, ao olhar para duração da paz como sendo somente entre Estados-soberanos há, propositalmente através da abstração, um esquecimento de grande parte da violência constituinte da história da humanidade (KRISHNA, 2006, p. 90).

A proposta de Krishna (2006) pode ser resumida como uma contrapontuação ("contrapuntuality") a um discurso nos estudos de Relações Internacionais que privilegia uma eternidade conceitual às características epistêmicas - soberania, nação, propriedade e Estado - através de dispositivos de abstração (KRISHNA, 2006, p. 91). Seguindo a proposta de Krishna (2006) é possível se distanciar das proposições reformistas, de acordo com Toledo (2013), de Roland Paris. Segundo Paris (2002), as OPs não têm, como tiveram as políticas coloniais, pressupostos de superioridade racial (PARIS, 2002, p. 652). Todavia, o entendimento do autor sobre raça é pautado por diferenças biológicas, que foram narradas como prova de evolução racial.

A fim de contrapontuar tal proposta analítica - que pressupõe ausência de relações raciais - é possível compreender raça não como um conceito estático, mas, 
assim como a fronteira, socialmente construído. Conforme observou Roxanne Lynn Doty (1993): “em vez de um relato histórico de como raça justificou determinadas práticas... nós precisamos relatar como raça foi construída por essas práticas"2 (DOTY, 1993, p. 457, tradução nossa). A autora então argumentou que textura de cabelo e cor de pele não são características raciais, mas sim construídas discursivamente como sendo de raças. Por essa proposta, a autora problematizou a fronteira a partir de como ela também produz e, consequentemente, é produzida pela raça: "Raça não somente cruza fronteiras, mas se torna o local onde fronteiras são produzidas"3 (DOTY, 1993, p. 457, tradução nossa).

Seguindo na análise sobre raça e fronteira como socialmente construídas em uma via de mão dupla entre elas e também com a paz, e considerando o contexto de inserção da região que hoje é chamada de Haiti a partir do encontro colonial iniciado com a "descoberta" das Américas por Cristovão Colombo, em 1492, será aberto adiante um diáologo com os estudos de Aníbal Quijano. Atento para como o encontro colonial no continente (hoje chamado de) americano foi e é constituinte da modernidade, o autor afirmou que foi a partir da colonização da América que os europeus desenvolveram um etnocentrismo pautado na distinção hierárquica racial (QUIJANO, 2005).

Dando atenção à hierarquia de raças, a contribuição de Quijano (2005), para este trabalho, pode ser destacada por dois pontos. 0 primeiro é que a hierarquização por raças, ainda existente, não é um conceito fixo - como proposto por Doty (1993) - e sim uma construção social pautada no controle da subjetividade dos indivíduos.

"Para tais regiões e populações [não-europeias], isso implicou um processo de reidentificação histórica, pois da Europa foram-lhe atribuídas novas identidades geoculturais... Em outras palavras, como parte do novo padrão de poder mundial, a Europa também concentrou sob sua hegemonia o controle de todas as formas de controle da subjetividade, da cultura, e em especial do conhecimento, da produção do conhecimento" (QUIJANO, 2005, p. 236)

Segundo Quijano (2005), as relações de poder do mundo atual são possíveis pelo controle da produção do conhecimento, sendo o entendimento do que é o melhor/o desenvolvido/o moderno uma construção eurocêntrica que classifica quem é evoluído e quem não é (QUIJANO, 2005, p. 236) - neste estudo, quem tem paz e quem recebe.

O segundo ponto é a hierarquia econômica ou financeira do mundo atual que reproduz e é reproduzida pelo controle da subjetividade. 0 autor argumentou que se há

\footnotetext{
${ }^{2}$ Original: "... instead of an historical account of how race justified certain practices... we need account of how race was constructed by these practices".

${ }^{3}$ Original: "Race does not just cross boundaries, but become a place where boundaries are produced".
} 
hoje uma divisão entre controladores da produção de produtos e produtores dos mesmos a explicação perpassa pela construção histórica da divisão racial mundial do trabalho, originada com a colonização das Américas (QUIJANO, 2005). 0 mercado mundial, desde a colonização, foi sendo dividido por raças; umas recebiam, outras não; umas controlavam a produção, outras produziam (QUIJANO, 2005, p. 232).

"As novas identidades históricas produzidas sobre a ideia de raça foram associadas à natureza dos papeis e lugares na nova estrutura global de controle do trabalho. Assim, ambos os elementos, raça e divisão do trabalho, foram estruturalmente associados e reforçando-se mutuamente"... (QUIJANO, 2005, p. 231)

A partir dessas contribuições de Quijano (2005) é possível analisar raça como um local de produção de fronteira que está relacionado com um controle da subjetividade em comunhão com determinada função no mercado de trabalho. A subjetividade está relacionada a como o conhecimento deve servir para assimilação do papel de determinada raça no mercado mundial capitalista (QUIJANO, 2005).

\section{Narrativas anfitriãs sobre a MINUSTAH à luz de uma análise crítica}

Antes de adentrarmos em um diálogo entre diferentes narrativas sobre a MINUSTAH, é necessário pontuar a questão racial e a produção de fronteira que envolve a relação com o Haiti. Quando analisada a participação brasileira na OP no Haiti, é importante observar que, em 2005, após um ano de participação brasileira, o então Ministro das Relações Exteriores do Brasil, Celso Amorim, ao abordar o assunto afirmou: "Nossa principal motivação foi a de evitar que o Haiti, a primeira república negra do mundo, seguisse abandonado" (AMORIM, 2005). Não somente o governo brasileiro, mas outros setores também têm compreendido o Haiti como negro. Isso pode ser observado pelo livro do jornalista Luis Kawaguti 'A república negra', no qual o autor conta sua experiência visitando o país negro que ainda possui meios de transportes como os do Brasil na década de 1970, por exemplo.

Tal relação entre negro e inferioridade/atraso no processo de desenvolvimento não é privilégio brasileiro. Na OP no Haiti, na década de 1990, o jornalista Doyle McManus denunciou que a operação Uphold Democracy, liderada pelos Estados Unidos, tinha como intenção principal evitar o fluxo de imigrantes haitianos; imigrantes negros (FARMER, 2006, p. 315). E essa identificação de inferioridade racial do Haiti ou dos haitianos ultrapassa as ações ou práticas de OPs. As relações com os Estados Unidos durante os séculos XIX e XX, desde a independência, estiveram cercadas por uma 
inferioridade racial haitiana (RENDA, 2001; FARMER, 2006). As relações ainda durante a colonização, fazendo eco às propostas de Quijano (2005), também foram marcadas por tal identificação (FICK, 1990; ROGERS, 2009).

As narrativas citadas acima além de convergirem com as propostas de Doty (1993) - há práticas que constroem raça - também apontam para como a identificação de inferioridade racial do Haiti contribuiu para diversos problemas que o Haiti enfretou/enfrenta. Por exemplo: subdesenvolvimento, desigualdade social por classes econômicas, urbanização desenfreada, falta de recursos públicos e inclusive as ditaduras entre 1957-1986 para não estender muito (RENDA, 2001; FARMER, 2006). Mantendo o foco na MINUSTAH, é importante identificar como a participação brasileira na OP já é uma aceitação de determinada narrativa, contrária às expostas acima.

No relatório S/2004/300, de 16/04/2004, o secretário-geral da ONU no Haiti identificou alguns problemas haitianos que demandavam uma operação de paz, problemas esses que foram classificados por Neto (2012) como "crise". A situação política no Haiti era marcada por uma falta de legitimidade de muitos governos locais, quebra de processos eleitorais e a existência de grupos armados em várias regiões do território nacional. Em contraposição, a ONU e a comunidade internacional são interpretados como potenciais fornecedores da paz, ignorando que, por exemplo, muitos dos grupos armados que não respeitavam governos locais - e também o nacional tiveram sua formação a partir da força militar haitiana que foi criada pelos Estados Unidos durante a ocupação de 1915-1934 e depois treinada pela CIA durante 30 anos de ditadura (FARMER, 2006).

Da mesma forma, a situação humanitária no relatório foi caracterizada por cerca de $80 \%$ da população vivendo abaixo da linha da pobreza e também por uma grande degradação do solo ocasionada por péssimas políticas agrícolas. A parte positiva no relatório ficou a cargo da ONU que proporcionou melhores condições de vida e de participação política aos camponeses. Em contraposição a essa dicotomia, o relatório não apontou que "péssimas políticas agrícolas" foram determinadas, também, pelos Estados Unidos - algo que foi reconhecido pelo ex-presidente do EUA, Bill Clinton, que disse: "Isso [política agrícola no Haiti] foi um erro... eu fiz isso". 4.

\footnotetext{
${ }^{4}$ Vídeo disponível em: https://www.youtube.com/watch?v=XtTeDv5FbNw. Acessado em: 26/07/2016. Original: "It [agriculture politics in Haiti] was a mistake... I did that".
} 
A partir dos exemplos acima é possível evidenciar que a narrativa do relatório da ONU, que foi base para a implementação da MINUSTAH, é uma forma específica de observar o contexto haitiano. Entretanto, é possível apontar que tal narrativa é uma maneira de controle da produção de conhecimento; o Haiti deve ser compreendido por uma específica lente. E ainda, ao participar como líder militar da operação, o Brasil está corroborando com esse controle da subjetividade haitiana.

No entanto, esse controle da subjetividade pode ser melhor observado a partir de duas contribuições fundamentais (que não poderiam ser feitas sem uma contrapontuação ao padrão de discussão atual); que indicam como relatórios da OP podem servir de controle da mão-de-obra haitiana. A primeira é um e-mail exposto pelo Wikileaks. 0 site que torna público diversos documentos de governos, há alguns anos divulgou um e-mail, de 2008. Com assunto "Por que nós precisamos de uma contínua presença da MINUSTAH no Haiti”5, origem em Porto Príncipe, capital haitiana, e dentre os destinatários Brasília, havia o seguinte trecho: “Uma saída prematura da MINUSTAH deixaria o governo de Preval ou de seu sucessor vulnerável a... forças políticas populistas e anti-economia de mercado - revertendo ganhos dos últismos dois anos"6 Em outro trecho é argumentado que a MINUSTAH é a principal instituição para alcançar alguns objetivos, dentre os quais "criar um ambiente de negócios".

Uma pergunta que pode surgir dessa economia de mercado e ambiente de negócios é: qual o papel dos haitianos e do Haiti? Para responder essa pergunta é válido destacar diferentes narrativas sobre como Préval e seu sucessor, Michel Martelly, se tornaram presidentes. No relatório S/2011/540, foi destacado que Martelly foi eleito com $67,57 \%$ dos votos o novo presidente do país. No entanto, o que foi comemorado pelos componentes da MINUSTAH (a realização de eleições democráticas no país e a sucessão do cargo presidencial democraticamente pela primeira vez na história haitiana) pode ser compreendida como uma eleição com baixa legitimidade. Tal

\footnotetext{
${ }^{5}$ Trecho original: "WHY WE NEED CONTINUING MINUSTAH PRESENCE IN HAITI".

${ }^{6}$ Disponível em: https://wikileaks.org/plusd/cables/08PORTAUPRINCE1381 a.html. Acessado em: 26/07/2016. Original: "A premature departure of MINUSTAH would leave the Preval government or his successor vulnerable to... resurgent populist and anti-market economy political forces - reversing gains of the last two years".
} 
afirmação é fundamentada nos dados de que os $67,57 \%$ descritos no relatório representam 15\% dos eleitores haitianos, uma vez que $78 \%$ não votaram7.

Para dar maior respaldo a afirmação anterior, é importante destacar que as eleições vencidas por Préval e Martelly não contaram com a participação de JeanBertrand Aristide, que teve cerca de $75 \%$ dos votos das urnas (da eleição anterior à MINUSTAH, em 2000) e sofreu um golpe, sendo impedido de participar das eleições que levaram Préval à presidência (Ibid.). Ainda é válido destacar que Aristide é apontado como um político haitiano que não é a favor de políticas econômicas de mercado (GERARD, 2005). Talvez esses fatos, não expostos no relatório S/2011/540, permitam entender por que um habitante de Cité Soleil, favela em Porto Príncipe, que foi guarda de Aristide e ficou 5 anos preso (2004-2009) sem julgamento, afirmou: "Isso é uma eleição de exclusão social; isso é uma seleção"8.

Através de uma narrativa diferente da exposta pela ONU e corroborada pelo Brasil, com sua participação na MINUSTAH, é compreensível o que um número de haitianos tem achado do seu papel na economia de mercado que parece ser um dos objetivos da MINUSTAH.

Em 2009, uma delegação de haitianos esteve no Brasil com o intuito de apontar alguns problemas que o povo haitiano passa devido a presença da MINUSTAH. Didier Dominique, representante do movimento dos trabalhadores Batay Ouvryie, afirmou que a operação de paz garante a "implantação de um projeto de extrema exploração dos trabalhadores" haitianos em indústrias têxteis. ${ }^{9}$ Enquanto a MINUSTAH garante uma economia de mercado no Haiti, costureiras haitianas têm um salário de US\$0,50/hora menor que o pago no Brasil (US\$3,27/hora), nos Estados Unidos (US\$16,92/hora) e até mesmo que o pago na China (US\$ 0,85), dados de 2009.10 Em entrevista para a TV Alesp, o senador haitiano Jean Charles Moise ao abordar o papel da MINUSTAH ponderou:

"Se acontece um caso de violência e nós chamamos a MINUSTAH, eles nos dizem que não estão lá para isso. A MINUSTAH está lá para reprimir as pessoas que se manifestam pela miséria, que pedem por emprego. A MINUSTAH não pode

\footnotetext{
7 TAFT-MORALES, Maureen. 'Haiti's National Elections: Issues, Concerns, and Outcomes'. Congressional Research Service, 2011. Página 10. Disponível em: https://www.fas.org/sgp/crs/row/R41689.pdf. Acessado em: 26/07/2016.

${ }^{8}$ Disponível em: http://www.thenation.com/article/haiti-abstains/. Acessado em: 26/07/2016. Original: "This is an election of social exclusion; this is a selection".

${ }^{9}$ Disponível em: http://www.sintufsc.ufsc.br/?p=1478. Acessado em: 26/07/2016.

${ }^{10}$ Ibid.
} 
trabalhar pela segurança mas pode reprimir as pessoas que tomam as ruas para reivindicar. Não é aceitável."11

A posição de Moises não é novidade no Brasil, uma vez que em 2009, junto à delegação da qual Dominique participou foram noticiados "relatos de desaparecimento de pessoas, de mão-de-obra infantil e de repressão violenta a greves e a mobilizações sindicais pela polícia local, referendadas pelas tropas da MINUSTAH..." e destacado a repressão violenta nas manifestações do dia dos trabalhadores, $1^{\circ}$ de março, que levou um manifestante à morte com um tiro na cabeça ${ }^{12}$.

Demonstrando que sua análise não é oposta ao e-mail divulgado pelo Wikileaks, alguns haitianos evidenciam que a exploração dos trabalhadores é acompanhada pelo controle da subjetividade haitiana - negra. Tal evidência pode ser melhor observada se comparada com o relatório S/2009/129, datado de 6 de março de 2009. Enquanto não há menção às narrativas anfitriãs, no relatório foi destacado: "Durante o período reportado, com apoio da MINUSTAH, um total de 14 projetos de trabalho intesivo foram completados em fevereiro, empregaram 11.688 trabalhadores, dos quais 3.500 (30\%) são mulheres"13 (S/2009/129, p. 7, tradução nossa).

As narrativas conflitadas até o momento são exemplos de como a produção de fronteira, analisada através das constribuições críticas sobre OPs, e de questões raciais, analisadas via diálogo entre propostas de Krishna, Doty e Quijano, merecem maior destaque na discussão sobre paz que ocorre no Brasil. Seguindo nessa direção será aberto um diálogo com a segunda contribuição fundamental: estudo de doutorado de Franck Seguy.

Seguy, haitiano, em doutorado realizado na UNICAMP (Universidade Estadual de Campinas) concluído em 2014, analisou como diversas políticas voltadas para a geração de empregos no Haiti fazem parte de um específico modelo de controle da subjetividade haitiana para uma economia de mercado. Enquanto Nasser (2012), Neto (2012), Aguilar (2014) e outros buscam entender a participação brasileira dentro de uma perspectiva de resolução de conflitos ou de interesse nacional, a contribuição de Seguy (2014) traz uma narrativa anfitriã para a paz imposta.

\footnotetext{
${ }^{11}$ Disponível em: https://www.youtube.com/watch?v=mQJgFnEffLs. Acessado em: 26/07/2016.

12 Disponível em: http://www1.folha.uol.com.br/mundo/2009/06/582350-no-senado-haitianos-pedem-quemissao-liderada-pelo-brasil-acabe.shtml. Acessado em: 26/07/2016.

${ }^{13}$ Original: "During the reporting period, with support from MINUSTAH, a total of 14 labour-intensive projects were completed by February, which employed 11,688 workers, of whom 3,500 (30 per cent) were women".
} 
Dentre relatórios, políticas e leis analisados por Seguy, trago aqui uma classificação do autor: os trabalhadores haitianos são um precariado (SEGUY, 2014, p. 75). Tal caracterização advém, segundo Seguy (2014), do baixo salário dos haitianos, das péssimas condições de trabalho nas indústrias e, principalmente, de como haitianos vêm sendo algo para uma economia de mercado que conta com empresas estrangeiras como controladoras da produção. Essa economia é analisa por Seguy através das propostas de Paul Collier, expressas em relatório de 2009 direcionado à ONU.

Collier, professor da University of Oxford, constatou que, desde 2007, o Haiti gozava de segurança, democracia e de oportunidades econômicas e argumentou que o país, pouco regulamentado, possuia mão-de-obra barata e experiente (SEGUY, 2014, p. 84). Tal observação está em sintonia com a análise de Quijano (2005) sobre a divisão laboral por raças desde a colonização: "Essa colonialidade do controle do trabalho determinou a distribuição geográfica de cada uma das formas integradas no capitalismo mundial" (QUIJANO, 2005, p. 235).

No entanto, o controle da subjetividade, como exposto por Seguy (2014) é ainda mais complexo. $\mathrm{O}$ autor apontou como Collier relacionou o precariado haitiano com a MINUSTAH: "exercer em cima da classe trabalhadora a pressão coercitiva imprescindível até a criação e aplicação de programas subsidiários eficazes para manter o consenso e a persuasão que permitirá economizar outra MINUSTAH" (SEGUY, 2014, p. 89 Apud. COLLIER, 2009). Relacionando a posição de Collier com o e-mail de 2008, ainda se pode surpreender mais quando acrescentado à análise o plano do governo haitiano 'Plano de Ordenamento do Norte/Nordeste: Corredor Cap-Ouanaminthe' no qual um dos objetivos explícitos é "liberar a mão-de-obra necessária para o desenvolvimento da indústria" (SEGUY, 2014, p. 92).

Uma das origens dessa mão-de-obra liberada é camponesa de Caracol, nordeste haitiano. A construção de uma zona franca têxtil em uma área de 250 hectares foi acordada entre o governo haitiano, a secretária de Estado dos EUA, representantes do BID (Banco Interamericano de Desenvolvimento) e da empresa têxtil sul-coreana Sae A Trading, no dia 11/01/2011 (SEGUY, 2014, p.92). A área que virou zona é a mesma onde antes trabalhavam e moravam 366 famílias, que tiveram suas casas expropriadas e não foram devidamente indenizados (SEGUY, 2014, p. 97). Esse processo gerou potenciais operários de produtos que não podem consumir. 
"O Haiti é visto como espaço para produzir, não como espaço para consumir. O trabalhador haitiano na zona franca, que produz as camisas, jeans ou tênis nunca vai consumir esses produtos. Por quê? Porque o salário dele, o salário do haitiano hoje, é de 200 gurdes (cerca de US\$ 5) ao dia. Quer dizer, está se utilizando do Haiti para produzir, mas não se enxerga o Haiti, o trabalhador haitiano, como um consumidor"14.

\section{Conclusão}

Com uma breve contextualização da discussão teórica no Brasil sobre paz em OPs, foi problematizado, através da ênfase na produção de fronteira, o recorte temporal que permeia toda a discussão. As escolhas analíticas de distintos autores e trabalhos, publicados em um curto período de tempo, quando confrontadas demonstram o recorte temporal que determinadas perspectivas teóricas têm sobre a construção da paz.

Influenciado pela perspectiva crítica este trabalho questionou a produção de fronteira que uma análise corrobora ou desconstrói. Buscando desconstruir o conceito de paz corroborado pela singularização da paz, questões raciais ganharam relevância na produção de fronteira. Todavia, toda a problematização discursiva aqui é pautada pelas atuais práticas - teóricas, onusianas e no terreno - que continuam construíndo fronteiras.

Assim, paz foi analisada a partir das escolhas analíticas haitianas. Indubitavelmente, há uma influência teórica que é assumida neste trabalho; todavia posições anfitriãs, de haitianos, permitiram duas contribuições fundamentais. Por um lado, a realização de um diálogo com distintas perspectivas teóricas através de relatos anfitriões. Por outro, questionamentos quanto à produção de fronteira e questões raciais e sua importância nos estudos brasileiros sobre paz em OPs.

\section{Bibliografia}

AGUILAR, Sérgio Luiz Cruz. 'As operações de paz como ferramenta para a construção da paz'. Em 'Reflexões Sobre a Paz'. Marília: Cultura Acadêmica, 2014.

AMORIM, Celso. 'Política Externa do Governo Lula: os dois primeiros anos'. Análise de Conjuntura OPSA, nำ 4, março de 2005.

ARAÚJO, Elizângela. Audiência Pública de delegação haitiana no Senado mostra caráter repressor das Forças Armadas de Paz da ONU. Site do SINTUFSC, 22 de junho de 2009. Disponível em: http://www.sintufsc.ufsc.br/?p=1478.

\footnotetext{
${ }^{14}$ Disponível em: http://www.unicamp.br/unicamp/ju/594/ajuda-internacional-ao-haiti-e-grande-mentiradefende-tese. Acessado em: 26/07/2016.
} 
ARCHIVES, Democracy Now!. 'We Made a Devils Bargain: Fmr. President Clinton Apologizes for Haiti Trade Policies 't'. Disponível em: https://www.youtube.com/watch?v=XtTeDv5FbNw.

BLANCO, Ramon. 'O processo de construção da paz da ONU: uma análise de suas falhas no Timor Leste'. Revista Brasileira Política Internacional, Vol. 58, No. 1 (2015).

CAMPOS, Marcela. No Senado brasileiro, haitianos pedem a missão liderada pelo Brasil acabe. Folha de São Paulo, 17 de junho de 2009. Disponível em: http://www1.folha.uol.com.br/mundo/2009/06/582350-no-senado-haitianos-pedemque-missao-liderada-pelo-brasil-acabe.shtml.

COUGHLIN, Dan. Haiti Abstains. The Nation, 22 de março de 2011. Disponível em: http://www.thenation.com/article/haiti-abstains/.

DIOGO, Adriano. 'Arena Livre - Senador Haitiano Jean Charles Moise'. Disponível em: https://www.youtube.com/watch?v=mQJgFnEffLs.

DOTY, Roxanne Lynn. 'The Bounds of 'Race' in International Relations'. MillenniumJournal of International Studies, vol. 22, n. 3, December 1993.

FARMER, Paul. 'The Uses of Haiti'. Estados Unidos: Comon Courage Press, 2006.

FICK, Carolyn E.. 'The Making of Haiti. The Saint Domingue Revolution from Below'. Knoxville: The University of Tennesse Press, 1990.

GIRARD, Philippe. 'Haiti. The Tumultuous History - From the Pearl of the Caribbean to Broken Nation'. Nova York: Palgrave Macmilla; 2005.

GOMES, Aureo de Toledo. 'Da paz liberal à virada local: avaliando a literatura crítica sobre peacebuilding'. Revista Monções, Vol. 2, No. 3, jul./dez. (2013).

JORNAL DA UNICAMP. 'Ajufa internaciona ao haiti é 'grande mentira, defende tese'. Disponível em: http://www.unicamp.br/unicamp/ju/594/ajuda-internacional-ao-haitie-grande-mentira-defende-tese.

KAWAGUTI, Luis. 'A República Negra: histórias de um repórter sobre as tropas brasileiras no Haiti'. São Paulo: Editora Globo; 2006.

KRISHNA, Sankaran. 'Race, Amnesia, and the Education of International Relations'. Em 'Decolonizing International Relations'. Rowman \& Littlefields Publishers, 2006.

MORENO, Marta, Carlos Chagas Vianna Braga e Maíra Siman Gomes, 'Trapped between many worlds: a postcolonial perspective on the UN mission in Haiti (MINUSTAH).' International Peacekeeping, Vol. 19, No. 3 (2012).

NASSER, Filipe. 'Pax Brasiliensis: projeção de poder e solidariedade na estratégia diplomática de participação brasileira em operações de paz da Organização das Nações Unidas' em Kai Michael Kenkel e Rodrigo Fracalossi de Moraes, orgs. 'O Brasil e as Operações de Paz em um Mundo Globalizado: Entre a tradição e a Inovação'. Brasília: IPEA, 2012.

NETO, Danilo Marcondes de Souza. 'O Brasil, o Haiti e a MINUSATH' em Kai Michael Kenkel e Rodrigo Fracalossi de Moraes, orgs. 'O Brasil e as Operações de Paz em um Mundo Globalizado: Entre a tradição e a Inovação'. Brasília: IPEA, 2012.

PARIS, Roland. 'International peacebuilding and the 'mission civilisatrice". Review of International Studies, 28, 2002. 
QUIJANO, Aníbal. 'A Colonialidade do Saber', em org. Lander, Edgard "A Colonialidade do Saber: eurocentrismo e ciências sociais". São Paulo, Cromosete Gráfica e Editora Ltda., 2005.

RENDA, Mary A.. "Taking Haiti. Military Occupation and the Culture of U.S. Imperialism, 1915-1940". Estados Unidos: The University of North Carolina Press, 2001.

ROGERS, Dominique. 'On the Road to Citizenship. The Complex Route to Integration of the Free People of Color in the Two Capitals of Saint Domingue'. Em David Patrick Geggus e Norman Fiering org. 'The World of the Haitian Revolution'. Bloomington: Indiana University Press, 2009.

Security Council of United Nations. 'S/2004/300'. Disponível em: http://www.un.org/en/peacekeeping/missions/minustah/reports.shtml.

Security Council of United Nations. 'S/2011/540'. Disponível em: http://www.un.org/en/peacekeeping/missions/minustah/reports.shtml.

Security Council of United Nations. 'S/2009/129'. Disponível em: http://www.un.org/en/peacekeeping/missions/minustah/reports.shtml.

SEGUY, Franck. 'A catástrofe de janeiro de 2010, a "Internacional Comunitária" e a recolonização do Haiti'. 2014. 299f. Tese de Doutorado - Instituto de Filosofia e Ciências Humanas. Universidade Estadual de Campinas, São Paulo. 2014.

TAFT-MORALES, Maureen. 'Haiti's National Elections: Issues, Concerns, and Outcomes'. Congressional Research Service, 2011. Página 10. Disponível em: https://www.fas.org/sgp/crs/row/R41689.pdf.

WIKILEAKS. 'WHY WE NEED CONTINUING MINUSTAH PRESENCE IN HAITI'. Disponível em: https://wikileaks.org/plusd/cables/08PORTAUPRINCE1381_a.html. 